Vol. 3 No. 1, Hal 24-28, Oktober 2021

\title{
Analisis Lapisan Hard Chrome dengan Heat Treatment terhadap Kekerasan dan Struktur Mikro pada Permukaan Baja Karbon S45C
}

\author{
Bambang Hari Priyambodo*, Margono, Kacuk Cikal Nugroho \\ Program Studi S1 Teknik Mesin, Sekolah Tinggi Teknologi Warga Surakarta, \\ Jl. Raya Solo Baki Km.2 Kwarasan, Sukoharjo, Jawa Tengah \\ *Penulis korespondensi: bambanghp@sttw.ac.id
}

Histori artikel: diserahkan 26 Juli 2021, direviu 15 Agustus 2021, direvisi 20 September 2021

\begin{abstract}
Generally, metals are easy to wear, so material modification is needed to increase hardness to increase the material's resistance to wear and tear. One way is to do a hard chrome plating process using the electroplating method and then continue the heat treatment process. This research was conducted to observe changes in the mechanical properties and microstructure of S45C steel that underwent hard chrome and heat treatment processes. This research was conducted by inserting $S 45 C$ steel as a cathode into hard chrome liquid and using lead $(\mathrm{Pb})$ as the anode. A positive (+) current powers the anode, the cathode has a negative current (-), the voltage used is $12 \mathrm{~V}$ with a duration of 60 minutes. After the cathode was coated with hard chrome, a hardness test was carried out, then continued with the heat treatment process using a temperature of $850^{\circ} \mathrm{C}$ for 30 minutes. The hardness test results show an increase in the hardness of $545 C$ steel that has been coated with hard chrome, with a hardness value of S45C steel $202.70 \mathrm{VHN}$, S45C hard chrome steel $998.63 \mathrm{VHN}$. The highest hardness value is S45C steel coated with hard chrome $998.63 \mathrm{VHN}$, increasing $392.7 \%$. Then the heat treatment process experienced a decrease in the hardness value, $528.90 \mathrm{VHN}$, with a percentage of $88.81 \%$. The results of the microstructure observation showed that the hard chrome layer that had been heated treated showed even cracks in the hard chrome layer.
\end{abstract}

Keywords: Electroplating, Hard Chrome, Heat Treatment, Hardness, Microstructure

DOI : https://doi.org/10.18196/jqt.v3i1.12284

WEB : https://journal.umy.ac.id/index.php/qt/article/view/12284

\section{PENDAHULUAN}

Hard chrome adalah salah satu lapisan pelindung yang paling banyak digunakan untuk meningkatkan sifat permukaan logam dengan kekerasan tinggi, ketahanan aus dan korosi yang baik serta koefisien gesekan yang rendah. Pembentukan lapisan tersebut, dapat merubah struktur dan meningkatkan berbagai sifat dengan pengaruh parameter proses (Priyambodo dan Kristiawan 2020). Saat ini, banyak teknik deposisi untuk menghasilkan lapisan krom keras seperti menggunakan thermal spary, physical vapour deposition (PVD), chemical vapour deposition (CVD) dan electro-deposition (Riyadi and Masyrukan 2017). Diantaranya, elektroplating adalah teknik yang sederhana dan murah. Proses ini dapat digunakan untuk menghasilkan lapisan dengan ketebalan yang bervariasi dalam kisaran ukuran mikro hingga nanometer (Menthe and Rie 1999); (Zhang et al., 2015); (Picas et al., 2006); (Priyambodo dan Yaqin 2018); (Priyambodo, 2011). Lapisan hard chrome dengan proses elektroplating diperkenalkan pada awal tahun 1930-an (Podgornik et al. 2018). Secara umum, digunakan untuk aplikasi yang mengalami keausan tinggi, seperti di otomotif dan industri manufaktur (Pfeiffer et al. 2011).

Meskipun lapisan hard chrome mampu meningkatkan kekerasan bahan secara signifikan, akan tetapi pada temperature kamar mengalami penurunan kelenturan (ductility) dan peningkatan brittleness sehingga mengurangi ketangguhan (toughness) bahan. Dimana usaha untuk meningkatan kekerasan sangat penting, akan tetapi bahan tidak boleh kehilangan sifat 
ketangguhannya. Material dengan kekerasan yang sangat tinggi tetap masih memerlukan sedikit sifat ketangguhan agar tidak mudah mengalami retak (crack) (Soltanieh et al., 2012). Selain itu, lapisan hard chrome masih mempunyai kekurangan pada daya lekatnya (Solehudin and Sumirat n.d.). Hal ini perlu diperhatikan mengingat daya lekat merupakan peranan penting dalam menentukan kualitas lapisan. Untuk meningkatkan daya lekat lapisan perlu dilakukan perlakuan panas.

Lapisan hard chrome dengan proses elektroplating, kemudian diberi perlakuan panas (heat treatment) bertujuan meningkatkan sifat mekanik dari suatu material. penelitian ini diharapkan baja karbon S45C yang telah dilapisi hard chrome dan di heat treatment akan memiliki sifat mekanik yang lebih baik dibandingkan logam induknya.

\section{METODE PENELITIAN}

Spesimen yang digunakan dalam penelitian ini adalah baja karbon S45C berbentuk batang berdiameter $20 \mathrm{~mm}$ dengan panjang $20 \mathrm{~mm}$ seperti Gambar 1. Permukaan dihaluskan dengan kertas amplas ukuran 400, 600, 800, 1000, dan 2000. Setelah dihaluskan dengan amplas, selanjutnya spesimen difinishing menggunakan autosol metal polish untuk menghilangkan goresan dan membuat permukaan spesimen lebih halus. Selanjutnya, mempersiapan larutan elektrolit asam krumat dan asam sulfat. Proses elektroplating pada baja karbon dengan lapisan hard chrome menggunakan tegangan 12 Volt dan waktu celup 60 menit. Selanjutnya, proses heat treatment menggunakan suhu $850{ }^{\circ} \mathrm{C}$ dengan waktu 30 menit dilakukan pada lapisan hard chrome dengan tegangan 12 Volt dan waktu celup 60 menit.

Pengujian kekerasan menggunakan standar ASTM E92 dengan pemberian beban $0,49 \mathrm{~N}$ selama 10 detik. Preparasi spesimen uji struktur mikro dilakukan proses polishing dengan autosol untuk menghaluskan permukaan. Spesimen yang sudah halus dilakukan proses etsa menggunakan larutan $1 \mathrm{ml} \mathrm{HNO}_{3}$ dan 20 $\mathrm{ml}$ alkohol. Permukaan spesimen diamati dengan menggunakan foto mikroskop optik. Pengujian stuktur mikro dilakukan untuk mengetahui perubahan kondisi struktur mikro pada permukaan baja karbon S45C yang terbentuk setelah dilakukan pelapisan dan heat treatment.

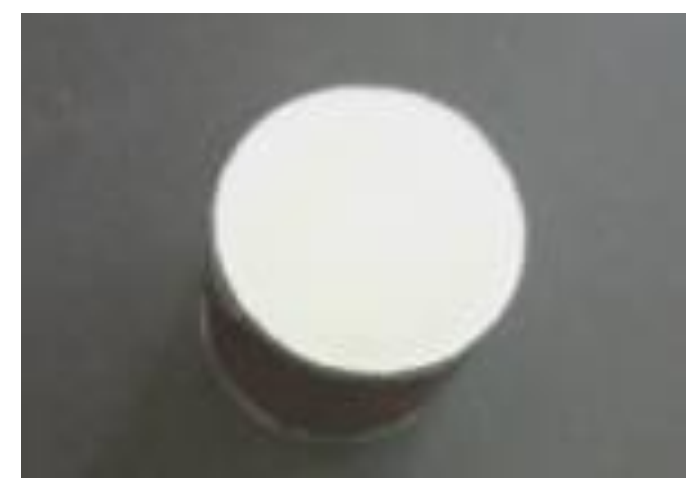

GAMBAR 1. Spesimen baja karbon S45C

\section{HASIL DAN PEMBAHASAN}

Pengujian kekerasan pada spesimen dilakukan sebelum dan sesudah dilakukannya pelapisan hard chrome. Pengukuran kekerasan lapisan hard chrome dan proses perlakuan panas dilakukan dengan menggunakan alat uji kekerasan jenis microhardness dengan metode vickers.

Hasil Kekerasan spesimen S45C sebelum dan setelah dilakukan pelapisan hard chrome dan heat treatment dapat dilihat pada gambar 2 . Kekerasan baja karbon S45C dengan lapisan hard chrome memiliki kekerasan tertinggi sebesar 998,63 VHN dibandingkan material non treatment dan lapisan hard chrome yang diberi perlakuan panas sebesar 202,70 VHN dan 528,90 VHN. Mengalami peningkatan kekerasan dibandingkan non treatment sebesar $329,7 \%$ dan penurunan kekerasan setelah di beri perlakuan panas sebesar $88,81 \%$. Penelitian ini membuktikan bahwa pelapisan hard chrome pada baja S45C dapat meningkatkan nilai kekerasan pada permukaan baja S45C dan proses heat treatment pada pelapisan hard chrome dapat menurunkan tingkat kekerasan pada lapisan hard chrome. Proses pelapisan hard chrome berpengaruh pada tingkat kekerasan baja S45C, dikarenakan atom chrome melapis pada permukaan baja S45C, sehingga kekerasannya meningkat. Sedangkan pada proses heat treatment menurunkan tingkat kekerasan pada lapisan hard chrome dikarenakan ikatan-ikatan atom pada lapisan hard chrome menjadi berkurang.

Pengujian kekerasan dan pengamatan struktur mikro hasil dari injakan identor pada 
penampang melintang spesimen baja S45C lapisan hard chrome. Hasil dari kekerasan pada daerah logam induk dan lapisan hard chrome dapat dilihat pada Gambar 3. Kekerasan lapisan hard chrome yang diperlihatkan pada titik 1,2, dan 3 memiliki nilai kekerasan lebih tinggi dibandingkan dengan logam induk. Gambar 4 ditunjukkan hasil pengujian struktur mikro jejak injakan identasi penampang melintang untuk substrat baja karbon S45C yang dilapisi hard chrome, dari hasil pengujian tersebut diperoleh peningkatan kekerasan pada jejak injakan paling kecil. Berdasarkan hasil pengujian menunjukkan bahwa makin kecil jejak injakan identasi maka semakin tinggi nilai kekerasannya.

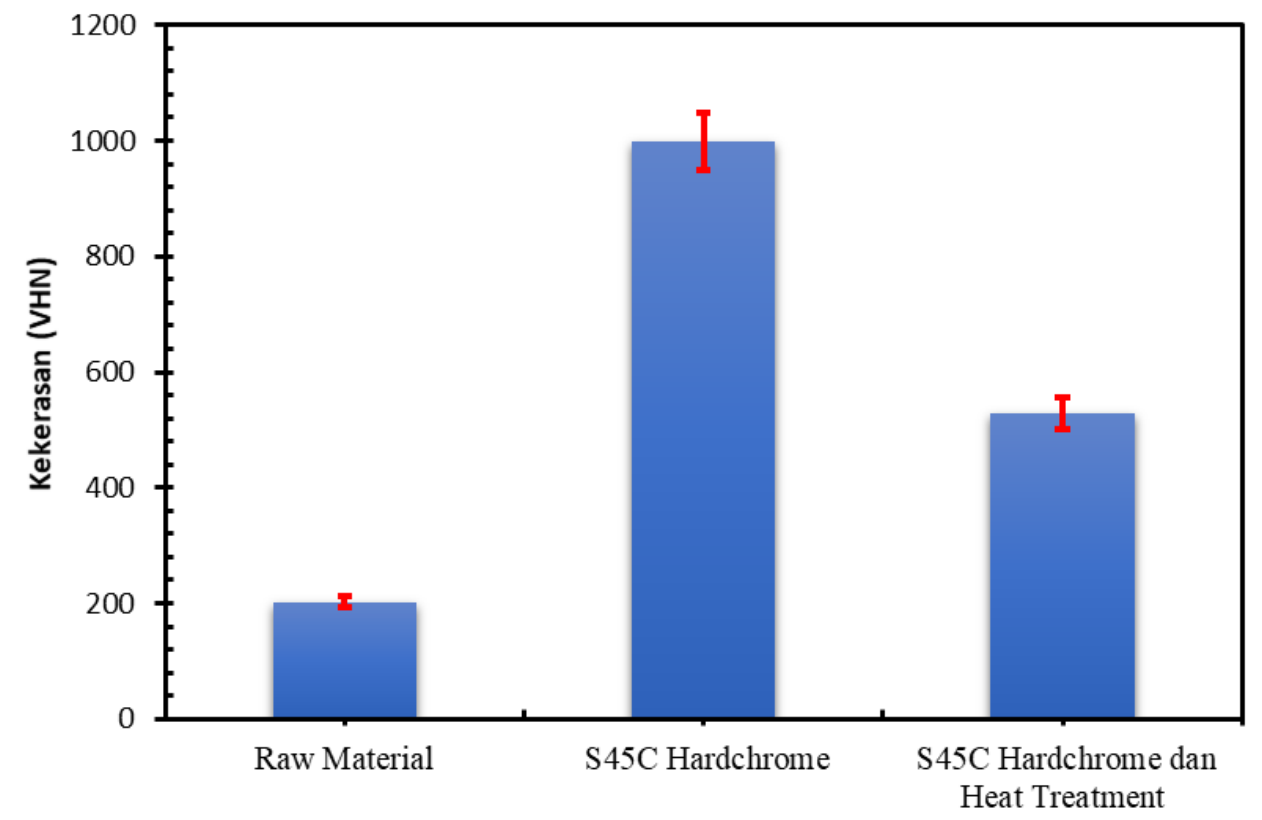

GAMBAR 2. Grafik nilai kekerasan sebelum dan sesudah proses elesktroplating serta perlakuan panas pada baja karbon $\mathrm{S} 45 \mathrm{C}$

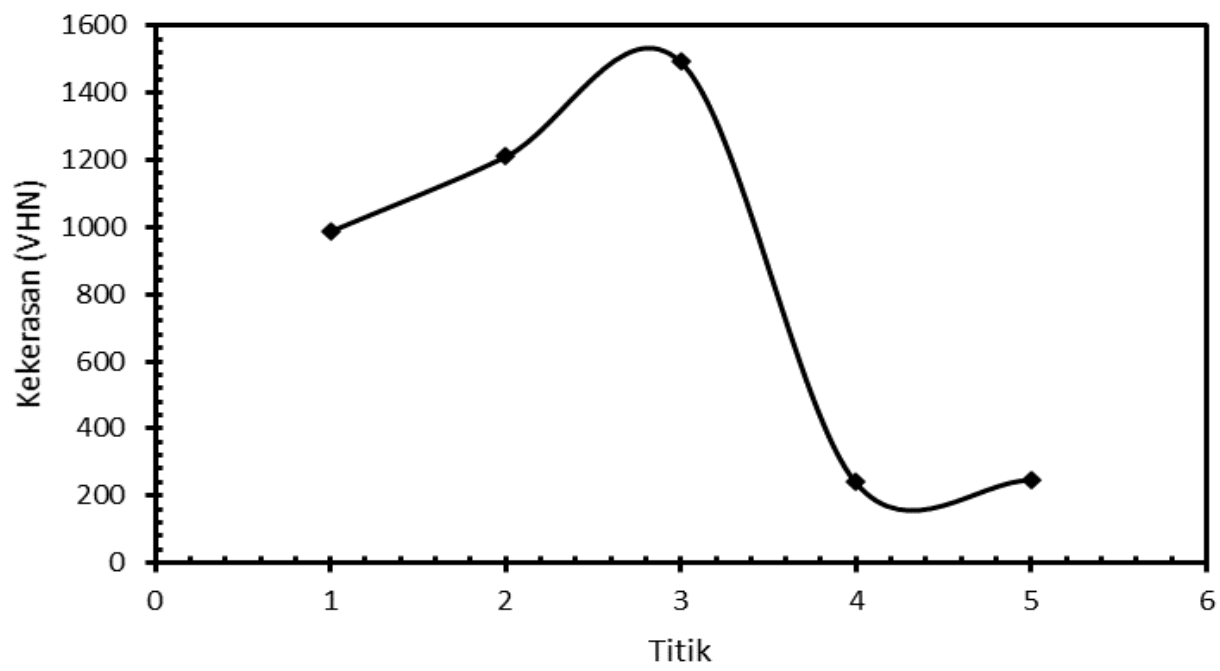

GAMBAR 3. Grafik nilai kekerasan pada titik logam induk dan lapisan hard chrome dengan penampang melintang 


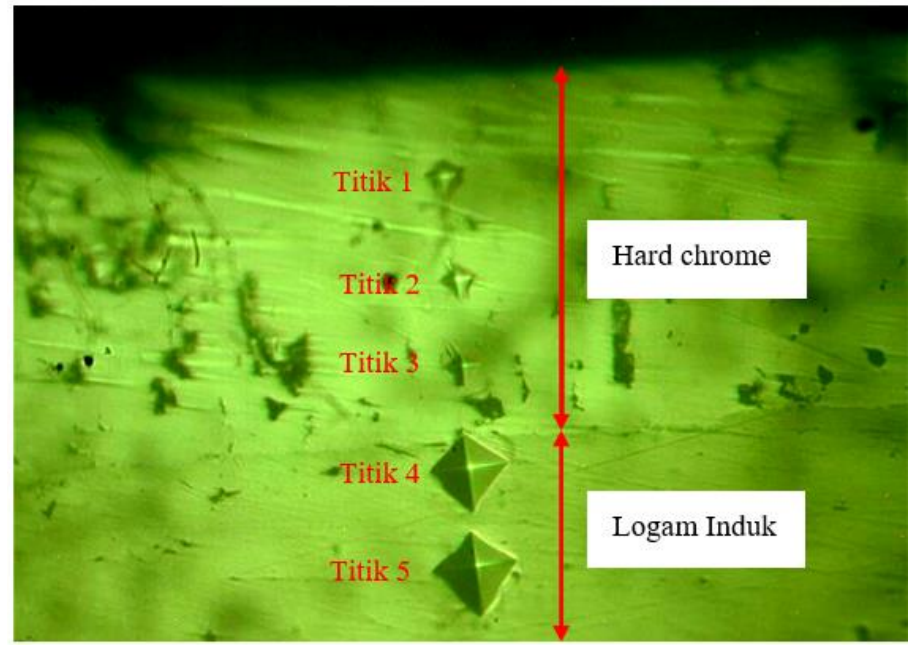

GAMBAR 4. Jejak penekanan baja S45C hard chrome dengan penampang melintang

Hasil pengamatan mikro struktur pada Gambar $6 \mathrm{~b}$ menunjukkan bahwa lapisan hard chrome yang telah dilakukan heat treatment terlihat jelas adanya retakan yang merata pada lapisan hard chrome. Retakan ini menunjukkan bahwa ikatan atom pada lapisan hard chrome menjadi berkurang dan ini yang menyebabkan lapisan hard chrome yang telah dilakukan proses heat treatment menjadi menurun nilai kekerasannya.
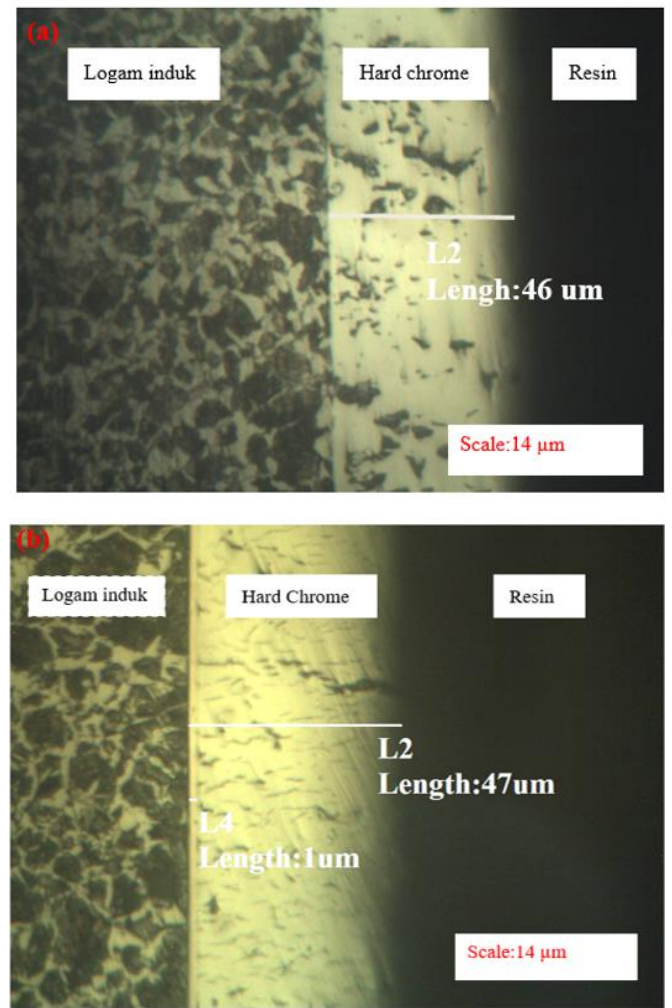

GAMBAR 5. Struktur mikro (a). Tebal lapisan hard chrome, dan (b) Tebal lapisan hard chrome yang telah heat Tretment dengan perbesaran $500 x$

\section{KESIMPULAN}

Hasil uji kekerasan pada baja karbon S45C, spesimen S45C Non treatment sebesar 202,70 VHN, lapisan hard chrome sebesar 998,63 VHN, dan lapisan hard chrome setelah di beri perlakuan panas sebesar 528,90 VHN. Kekerasan baja karbon S45C menggunakan lapisan hard chrome lebih tinggi dibandingkan dengan spesimen lainnya. Hasil pengamatan struktur mikro lapisan yang terbentuk setelah dilakukan proses electroplating dan heat treatment terlihat jelas adanya retakan yang merata pada lapisan hard chrome. Retakan menunjukkan bahwa ikatan atom pada lapisan hard chrome menjadi berkurang dan menyebabkan lapisan hard chrome setelah proses heat treatment menurun nilai kekerasannya.

\section{UCAPAN TERIMA KASIH}

Terimakasih kepada Laboratorium Pengujian Logam Sekolah Tinggi Teknologi "Warga" Surakarta yang telah memberikan fasilitas dalam menyelesaikan penelitian ini.

\section{DAFTAR PUSTAKA}

Menthe, E. and K. T. Rie. 1999. "Plasma Nitriding and Plasma Nitrocarburizing of Electroplated Hard Chromium to Increase the Wear and the Corrosion Properties." Surface and Coatings Technology 112(1-3):217-20. 
Priyambodo, B.H., and Kristiawan, Y., 2020. "Pengaruh Durasi Hard Chrome Terhadap Kekerasan dan Struktur Mikro Baja Karbon S45C." Jurnal Crankshaft 3 (2).

Pfeiffer, Wulf, Christof Koplin, E. Reisacher, and J. Wenzel. 2011. "Residual Stresses and Strength of Hard Chromium Coatings." Materials Science Forum 681:133-38.

Picas, J. A., A. Forn, and G. Matthäus. 2006. "HVOF Coatings as an Alternative to Hard chrome for Pistons and Valves." Wear 261(5-6):477-84.

Priyambodo, B.H., and Yaqin, R.I., 2018. "Studi Durasi Electroplating Ni-Cr pada AISI 316L terhadap Laju Korosi dalam Media 3,5\% NaCl." Konferensi Ilmiah Teknologi Texmaco 1, 99-103.

Priyambodo, B.H., 2011. "Pengaruh Kuat Arus terhadap Kekerasan, Struktur Mikro dan Laju Korosi Lapisan Chromate Coating pada Logam Aluminium." Universitas Gadjah Mada.

Podgornik, B., O. Massler, F. Kafexhiu, and M. Sedlacek. 2018. "Crack Density and Tribological Performance of HardChrome Coatings." Tribology International 121(January):333-40. Retrieved (https://doi.org/10.1016/j.triboint.2018.0 1.055).

Riyadi, Tri Widodo Besar and Masyrukan. 2017. "Hardness and Wear Properties of Laminated Cr-Ni Coatings Formed by Electroplating." AIP Conference Proceedings 1831:020034-36.

Riyadi, Tri Widodo Besar, Sarjito, Masyrukan, and Ricky Ary Riswan. 2017. "Mechanical Properties of $\mathrm{Cr}-\mathrm{Cu}$ Coatings Produced by Electroplating." AIP Conference Proceedings 1855(June 2017).

Solehudin, Agus and Uum Sumirat. n.d. "Pengaruh Temperatur Perlakuan Panas Hasil Pelapisan Cu-Ni Pada Baja Karbon ST-37 Terhadap Sifat Mekanik." (207):1-7.

Soltanieh, M., H. Aghajani, F. Mahboubi, and Kh A. Nekouee. 2012. "Surface Characterization of Multiple Coated H11 Hot Work Tool Steel by Plasma Nitriding and Hard Chromium Electroplating Processes." Vacuum
86(10):1470-76. Retrieved (http://dx.doi.org/10.1016/j.vacuum.201 2.01.003).

Zhang, Hui, Liaowang Liu, Jingsheng Bai, and Xingbo Liu. 2015. "Corrosion Behavior Andmicrostructure of Electrodeposited Nano-Layered Ni-Cr Coatings." Thin Solid Films 595:36-40. Retrieved (http://dx.doi.org/10.1016/j.tsf.2015.10. 046). 